\title{
The tailoring of impact ionization phenomenon using pseudomorphic structures-applications to InGaAIAs on GaAs and InP substrates
}

\author{
Jasprit Singh \\ Department of Electrical Engineering and Computer Science, The University of \\ Michigan, Ann Arbor, MI 48109, USA
}

\begin{abstract}
In this paper the potential of utilizing strain for suppressing impact ionization is evaluated. It is found that if compressive strain is introduced without altering the bandgap (e.g. by using properly tailored InGaAlAs alloys) the threshold energy for electron impact ionization is significantly increased for both GaAs-based and InP-based materials.
\end{abstract}

Pseudomorphic devices such as n-type $\operatorname{In}_{x} \mathrm{Ga}_{1-x} /$ AlGaAs (grown on GaAs) and $\mathrm{In}_{0.53+x} \mathrm{Ga}_{0.47-x} \mathrm{As} /$ $\mathrm{In}_{0.52} \mathrm{Al}_{0.48} \mathrm{As}$ (grown on InP) MODFET structures are now routinely being used for high-frequency applications. While the speed-related improvements are well documented, so far, strain has not been utilized to alter and control breakdown performance. Breakdown related to impact ionization is important in a variety of device applications and is usually tailorable only by altering the bandgap. However, the large changes in valence bandstructure due to strain [1-4] suggest that electron impact ionization could be tailored by strain. This is because the severe constraints due to simultaneous satisfaction of energy and momentum conservation for the scattering particles are very much dependent on the carrier masses.

Two issues are examined in this paper: (i) how the impact ionization rates are altered if excess In is added to GaAs and $\operatorname{In}_{0.53} \mathrm{Ga}_{0.4} \mathrm{As}$ which are initially lattice matched to GaAs and InP respectively; (ii) how the impact ionization rates are affected if in addition to excess In we also add excess $\mathrm{Al}$ to maintain a constant bandgap. In the second case, the bandgap is maintained constant while the compressive strain is introduced by excess In. The motivation for examining the second possibility will become clear after we present our results. The in-plane lattice constant is matched to GaAs for one set of calculations and InP for the other case. The amount of maximum strain $(\sim 2 \%)$ is used in pseudomorphic devices. The compressive in-plane strain produced by addition of excess In in the channel reduces the valence band density of states mass considerably. These results have been reported in considerable detail both experimentally and theoretically [5-7]. It is important to note that the reduction in the hole mass is dependent primarily upon the strain and not on the chemical composition of the material. Note that cases are included where the reduction of bandgap produced by excess In is compensated for by the addition of excess $\mathrm{Al}$, while maintaining the strain.

The electron impact ionization rates are addressed since they are calculated to be affected much more due to bandstructure modifications.

The impact ionization rate can be written as (in CGS units) [8]

$$
\begin{aligned}
W_{\text {impact }}\left(E_{k 1}\right)=\frac{4 \pi}{\hbar}\left(\frac{e^{2}}{2 \pi \varepsilon}\right)^{2} \frac{\hbar^{2} P c v^{2}}{m^{2} E_{g}^{2}} \\
\times \int \frac{\delta\left(E_{k 1}-E_{g}-E_{k 2}-E_{k i^{\prime}}-E_{k 2^{\prime}}\right) \mathrm{d}^{3} k_{i^{\prime}} \mathrm{d}^{3} k_{2}}{\left|k_{1}-k_{i^{\prime}}\right|^{2}}
\end{aligned}
$$

where $E_{k 1}$ and $E_{k 2}$ are the energies of the starting electrons and $E_{k 1}, E_{k 2}$, are the energies of the final electrons. $P c v$ is the momentum matrix element and we have obtained its value from the work of Lawaetz [9]. The integral in equation (2) is numerically integrated.

The impact ionization rates are plotted in figures 1 and 2 for the GaAs-based and InP-based structures. The corresponding threshold energies are also given in the figure captions. Two important points are to be noted. As excess In is added to make the structure pseudomorphic, the impact ionization thresholds increase slightly for GaAs-based structures but decrease slightly for the InP. based structures. The decrease in the threshold is much more rapid for an unstrained alloy for which the hole masses do not decrease with added In but the bandgap decreases. In the pseudomorphic case, while the decrease in bandgap decreases the threshold for breakdown, the decreasing hole mass in the pseudomorphic structure 


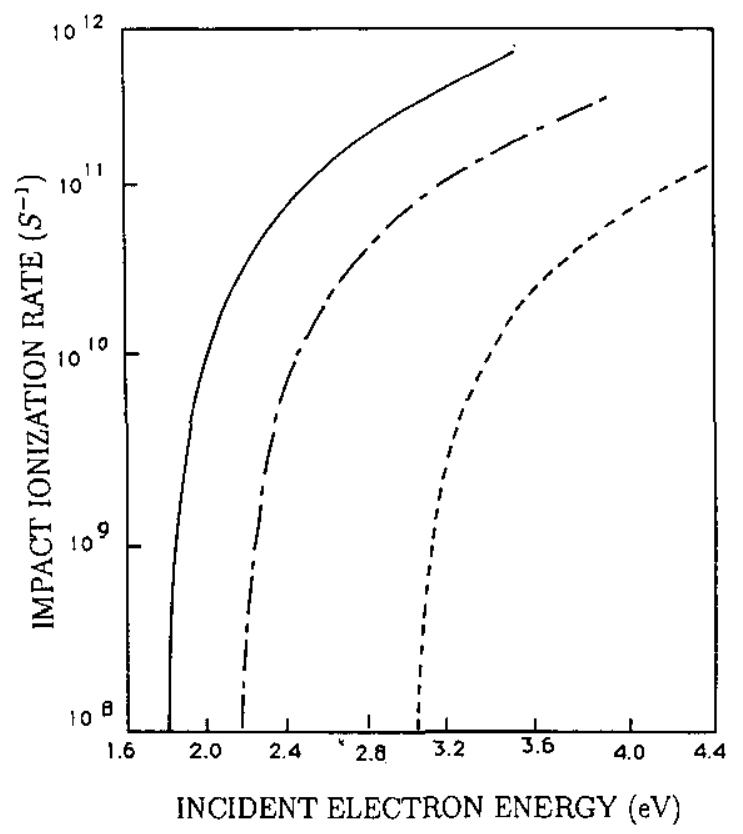

Figure 1. Impact ionization rates for several material systems grown on GaAs substrates. Full curve$\operatorname{GaAs}\left(E_{\mathrm{g}}=1.41 \mathrm{eV} ; E_{/ \hbar}=1.9 \mathrm{eV}\right)$; chain curve$\ln _{0.2} \mathrm{Ga}_{0.8}$ As $\left(E_{\mathrm{g}}=1.25 \mathrm{eV} ; E_{/ \hbar}=2.2 \mathrm{eV}\right)$; broken curve$\ln _{0.2} \mathrm{Al}_{0.18} \mathrm{Ga}_{0.62} \mathrm{As}\left(E_{\mathrm{g}}=1.41 \mathrm{eV} ; E_{/ h}=3.1 \mathrm{eV}\right)$

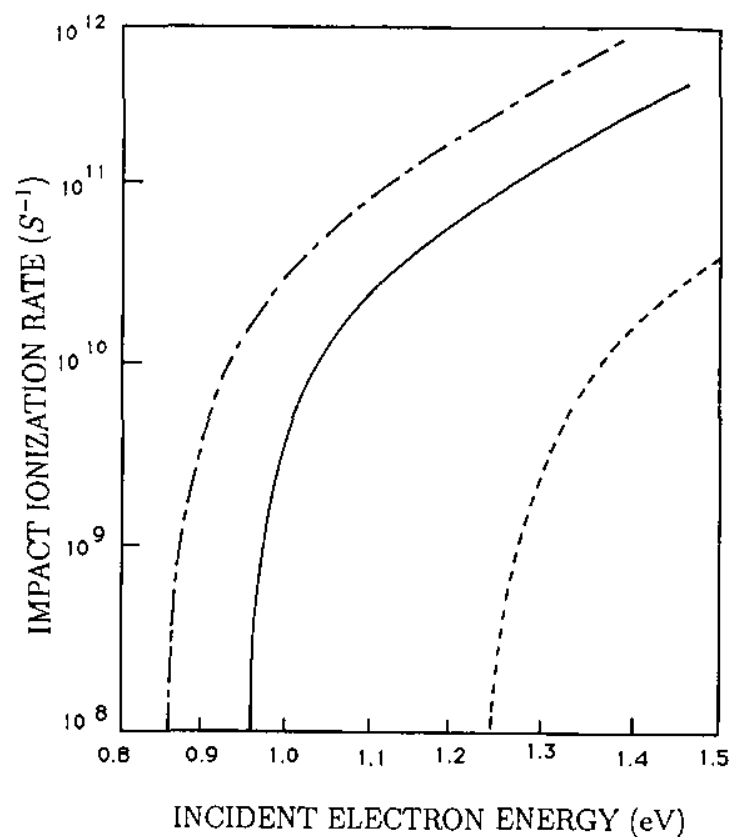

Figure 2. Impact ionization rates for structures grown on InP structures. Full curve- $\ln _{0.53} \mathrm{Ga}_{0.47} \mathrm{As}\left(E_{\mathrm{g}}=0.8 \mathrm{eV}\right.$; $\left.E_{h \mathrm{~h}}=0.95 \mathrm{eV}\right)$; chain curve- $\ln _{0.73} \mathrm{Ga}_{0.27}$ As $\left(E_{\mathrm{q}}=0.62 \mathrm{eV}\right.$; $\left.E_{/ h}=0.87 \mathrm{eV}\right)$; broken curve- $\ln _{0.73} \mathrm{Ga}_{0.12} \mathrm{Al}_{0.15} \mathrm{As}$ $\left(E_{\mathrm{g}}=0.8 \mathrm{eV} ; E_{h}=1.2 \mathrm{eV}\right)$

Table 1. A list of material compositions and parameters used in the calculations. The hole density of states mass is calculated from the four-band $k \cdot p$ theory and the electron band is non-parabolic with the non-parabolicity factor as given.

\begin{tabular}{|c|c|c|c|c|c|}
\hline Material & $\begin{array}{l}\text { Bandgap } \\
(\mathrm{eV})\end{array}$ & Electron mass & $\begin{array}{l}\text { Hole mass } \\
\text { (DOS) }\end{array}$ & $\begin{array}{l}\text { Non-parabolicity } \\
\left(\mathrm{eV}^{-i}\right)\end{array}$ & $\begin{array}{l}E_{/ h} \\
(\mathrm{eV})\end{array}$ \\
\hline $\begin{array}{l}\mathrm{GaAs} \\
\mathrm{In}_{0.1} \mathrm{GaAs} \\
\mathrm{In}_{0.20} \mathrm{Ga}_{0.8} \mathrm{As} \\
\mathrm{In}_{0.1} \mathrm{Al}_{0.08} \mathrm{Ga}_{0.82} \mathrm{As} \\
\mathrm{In}_{0.2} \mathrm{Al}_{0.18} \mathrm{Ga}_{0.62} \mathrm{As} \\
\ln _{0.53} \mathrm{Ga}_{0.47} \mathrm{As} \\
\mathrm{In}_{0.63} \mathrm{Ga}_{0.37} \mathrm{As} \\
\mathrm{In}_{0.73} \mathrm{Ga}_{0.27} \mathrm{As} \\
\ln _{0.63} \mathrm{Ga}_{0.3} \mathrm{Al}_{0.07} \mathrm{As} \\
\ln _{0.73} \mathrm{Ga}_{0.12} \mathrm{Al}_{0.15} \mathrm{As} \\
\mathrm{In}_{0.8} \mathrm{Al}_{0.2} \mathrm{As}\end{array}$ & $\begin{array}{l}1.41 \\
1.33 \\
1.25 \\
1.41 \\
1.41 \\
0.8 \\
0.72 \\
0.62 \\
0.8 \\
0.8 \\
0.8\end{array}$ & $\begin{array}{l}0.067 \\
0.064 \\
0.062 \\
0.067 \\
0.067 \\
0.044 \\
0.042 \\
0.037 \\
0.044 \\
0.044 \\
0.044\end{array}$ & $\begin{array}{l}0.45 \\
0.3 \\
0.2 \\
0.3 \\
0.2 \\
0.45 \\
0.3 \\
0.2 \\
0.3 \\
0.2 \\
0.15\end{array}$ & $\begin{array}{l}0.6 \\
0.6 \\
0.6 \\
0.6 \\
0.6 \\
1.0 \\
1.0 \\
1.0 \\
1.0 \\
1.0 \\
1.0\end{array}$ & $\begin{array}{l}1.9 \\
2.0 \\
2.2 \\
2.2 \\
3.1 \\
0.95 \\
0.9 \\
0.87 \\
1.05 \\
1.2 \\
1.45\end{array}$ \\
\hline
\end{tabular}

partially compensates for this. However, if the strain is introduced by addition of excess In but the bandgap is maintained by excess $A l$, dramatic improvement in the impact ionization threshold is observed, as is evident from figures 1 and 2 . Normally such high threshoids are only expected for much larger bandgap materials. It is found that for the GaAs-based structures, the threshold energy increases from $1.9 \mathrm{eV}$ for the lattice-matched structure to $3.1 \mathrm{eV}$ for a structure with $2 \%$ strain. In InPbased structures the threshold increases from $0.9 \mathrm{eV}$ to $1.2 \mathrm{eV}$ for $2 \%$ strain and to $1.45 \mathrm{eV}$ for $2.5 \%$ strain. To find the electric field dependence of the impact ionization rate and to predict the breakdown voltages, we are now in the process of carrying out Monte Carlo simulations.

The increased breakdown thresholds suggested by the theory for cases where bandgap is maintained but compressive strain is introduced using excess In and Al have not yet been tested experimentally. Since a number of devices can benefit by this large tailoring of impact ionization rates it would be worthwhile to test these possibilities experimentally. It is important to note that the predicted benefits can arise only because of pseudomorphic epitaxy, since it is essential to maintain a constant bandgap and produce a uniaxial strain to lift the light-hole-heavy-hole degeneracy.

\section{Acknowledgment}

This work was supported by the Army URI program. (Grant No DAAL03-87-K-0007). 


\section{References}

[1] Jones E, Fritz I, Schirber J, Smith $\mathbf{M}$ and Drummond T 1987 Gallium Arsenide and Related Compounds 1986 (Inst. Phys. Conf. Ser. 83) pp 227-33

[2] Drummond T, Zipperian T, Fritz I, Schirber J and Plut T 1986 Appl. Phys. Lett. 49 461-3

[3] Hinckley J and Singh J 1988 Appl. Phys. Lett. 53 785-8

s.
[4] Lee C, Wang H, Sullivan G, Sheng N and Miller D 1987 IEEE Trans. Electron Device Lett. EDL-8 85-7

[5] Jaffe M and Singh J 1989 J. Appl. Phys. 65 329-38

[6] Jaffe M, Oh J E, Pamulapati J, Singh J and Bhattacharya P 1989 Appl. Phys. Lett. 54 2345-6

[7] Zipperian T E, Dawson L R, Drummond T, Schinber J E and Fritz I J 1988 Appl. Phys. Lett. 52 975-7

[8] Ridley B K 1982 Quantum Processes in Semiconductors (Oxford: Oxford University Press)

[9] Lawetz P 1971 Phys. Rev. B 4 3460-7 